Abstract P2-S1.07 Table 1 Self-reported sexual activity and response to questions about school, home, and mental health among female adolescents in a largely African American inner-city clinic in the Southeastern USA $(N=743)$

\begin{tabular}{|c|c|c|c|c|c|c|}
\hline \multirow{2}{*}{$\begin{array}{l}\text { Responses to questions about } \\
\text { school, home, and mental health }\end{array}$} & \multicolumn{3}{|c|}{ Number of partners in past 90 days } & \multicolumn{3}{|c|}{ Correct and consistent condom use $\dagger$} \\
\hline & $0-1$ & $2+$ & OR $(95 \% \mathrm{CI})^{*}$ & No & Yes & OR $(95 \% \mathrm{CI})^{*}$ \\
\hline \multicolumn{7}{|c|}{ "My school work is poor" (in the last 6 months) } \\
\hline Not true & $317(67 \%)$ & $153(33 \%)$ & Referent & $340(81 \%)$ & $80(19 \%)$ & Referent \\
\hline Sometimes true & $79(54 \%)$ & $68(46 \%)$ & $1.78(1.22 \text { to } 2.60)^{*}$ & $123(90 \%)$ & $13(10 \%)$ & $0.45(0.24 \text { to } 0.84)^{*}$ \\
\hline True & $19(41 \%)$ & $27(59 \%)$ & $2.94(1.59 \text { to } 5.46)^{*}$ & $34(81 \%)$ & $8(19 \%)$ & $1.0(0.45$ to 2.24$)$ \\
\hline \multicolumn{7}{|c|}{ "I run away from home"(in the last 6 months) } \\
\hline Not true & $378(67 \%)$ & $186(33 \%)$ & Referent & $416(82 \%)$ & $90(18 \%)$ & Referent \\
\hline Sometimes true & $20(34 \%)$ & $39(66 \%)$ & $3.96(2.245 \text { to } 6.99)^{*}$ & $46(85 \%)$ & $8(15 \%)$ & $0.80(0.37$ to 1.76$)$ \\
\hline True & $18(44 \%)$ & $23(56 \%)$ & $2.60(1.37 \text { to } 4.93)^{*}$ & $36(92 \%)$ & $3(8 \%)$ & $0.39(0.12$ to 1.28$)$ \\
\hline \multicolumn{7}{|c|}{ "I am unhappy, sad or depressed"(in the last 6 months) } \\
\hline Not true & $271(72 \%)$ & $107(28 \%)$ & Referent & $255(77 \%)$ & $77(23 \%)$ & Referent \\
\hline Sometimes true & $154(57 \%)$ & $117(43 \%)$ & $1.92(1.39 \text { to } 2.67)^{*}$ & $220(88 \%)$ & $31(12 \%)$ & $0.47(0.30 \text { to } 0.74)^{*}$ \\
\hline True & $50(54 \%)$ & $42(46 \%)$ & $2.13(1.33 \text { to } 3.39)^{*}$ & $74(88 \%)$ & $10(12 \%)$ & $0.45(0.22 \text { to } 0.91)^{*}$ \\
\hline \multicolumn{7}{|c|}{ Saw a counsellor about emotional problems (in past 90 days) } \\
\hline No & $431(66 \%)$ & $225(34 \%)$ & Referent & $481(81 \%)$ & $113(19 \%)$ & Referent \\
\hline Yes & $45(52 \%)$ & $41(48 \%)$ & $1.75(1.11 \text { to } 2.74)^{*}$ & $69(93 \%)$ & $5(7 \%)$ & $0.31(0.12 \text { to } 0.78)^{*}$ \\
\hline
\end{tabular}

${ }^{*}$ Statistics printed in bold font have ORs in comparison to their referent of $p<0.05$.

†A respondent was classified as having correct and consistent condom use if her responses indicated that, during the past 90 days ALL of the following were true: she had engaged in vaginal sexual intercourse at least once, a condom had been used during all vaginal sexual intercourse, the condom was always put on prior to genital contact and remained on throughout sexual intercourse, a condom had never broken while being worn, and a condom had never been put on inside out and then flipped over and put back on again.

likely to report correct and consistent condom use, $\mathrm{OR}=0.45(95 \%$ CI 0.22-to 0.91) (Abstract P2-S1.07 table 1). Those who reported seeing a counsellor for emotional problems (13\% of the sample) were more likely to report multiple partners, $\mathrm{OR}=1.75(95 \% \mathrm{CI} 1.11$ - to 2.74) and less likely to report correct and consistent condom use, $\mathrm{OR}=0.31$ (95\% CI 0.12-to 0.78) than those who reported no such counselling. Poor school performance and running away from home were associated with having more than one partner, but generally not with inconsistent or incorrect condom use. (Abstract P2-S1.07 table 1).

Conclusion Our results highlight the importance of mental health and sexual behaviour assessments in adolescent healthcare settings. Further research is needed to assess whether counselling and improved emotional well-being can reduce sexual behaviours that place adolescents at risk

\section{P2-S1.08 DUAL CONTRACEPTIVE USE AMIONG ADOLESCENTS AND YOUNG ADULTS: CORRELATES AND IMPLICATIONS FOR CONDOM USE AND STI OUTCOMES}

doi:10.1136/sextrans-2011-050108.286

${ }^{1} \mathrm{~J}$ Hood, ${ }^{1} \mathrm{M}$ Hogben, ${ }^{2} \mathrm{M}$ Chartier, ${ }^{1} \mathrm{G}$ Bolan, ${ }^{3} \mathrm{H}$ Bauer. ${ }^{1} \mathrm{CDC}$, Atlanta, USA; ${ }^{2}$ Department of Veteran Affairs, USA; ${ }^{3}$ California Department of Public Health, USA

Background Simultaneous use of condoms and other contraceptive methods ("dual use") provides the maximum protection against unintended pregnancies and sexually transmitted disease (STD). Some studies show condom use wanes among dual users, thus potentially increasing STD risk. The purpose of this study is to (1) demonstrate how the composition of comparison groups influence conclusions regarding condom use and STD risk among hormonal contraceptive (HC) users and (2) assess the correlates of dual use.

Methods A convenience sample of youth ages $12-25$ years $(n=1450)$ were screened for chlamydia and gonorrhoea at non-clinical sites in high morbidity neighbourhoods of two California counties in 2002-2003. Gender-specific ORs for three outcomes (condom use consistency, condom use at last sex, and positive STD result) were calculated for three separate comparisons: (1) HC vs non-HC users, (2) HC vs condom only users, and (3) dual vs condom only users. Multivariate logistic regression models were constructed to assess the correlates of dual use.
Results Each of the three comparisons led to different conclusions (see Abstract P1-S1.08 table 1). For our broadest comparison (HC vs non-HC users), female HC users were less likely to screen positive for an STD. However, males who reported that their partners used $\mathrm{HC}$ were less likely to report frequent condom use. In the second comparison ( $\mathrm{HC}$ vs condom only), condom use at last sex and frequent condom use was significantly less common among HC users than condom only users. In the final comparison, dual users did not differ from condom-only users. Sex, age, race, and relationship tenure were significant correlates of dual use. Females were more likely to report dual use $[\mathrm{aOR}=1.6$ (1.1 to 2.3)], as were older adolescents ( $16-18$ years) vs young adolescents (12-15 years) $[\mathrm{aOR}=2.1$ (1.3 to 3.3)]. Relative to Whites, African Americans and Hispanics were less likely to report dual use [AA: aOR $=0.4$ (0.2 to $0.6)$; Hisp: $\mathrm{aOR}=0.5$ (0.3 to 0.7$)$ ]. Respondents in longer-term relationships were more likely to report dual use than respondents in new relationships.

Abstract P2-S1.08 Table 1 Odds of condom use and STD acquisition

\begin{tabular}{|c|c|c|c|}
\hline & $\begin{array}{l}\text { A. HC vs No HC } \\
\text { aOR }(95 \% \text { Cl) }\end{array}$ & $\begin{array}{l}\text { B. HC vs Condom } \\
\text { Only aOR ( } 95 \% \text { CI) }\end{array}$ & $\begin{array}{l}\text { C. Dual Use vs } \\
\text { Condom Only } \\
\text { aOR (95\% CI) }\end{array}$ \\
\hline \multicolumn{4}{|l|}{ Females } \\
\hline Condom use at last sex & $1.18(0.83$ to 1.68$)$ & $0.49(0.33$ to 0.71$)) \neq$ & $1.23(0.79$ to 1.93$)$ \\
\hline Frequent condom use & 1.41 (0.97 to 2.05$)$ & $0.29(0.19$ to 0.45$) \neq$ & 1.55 (0.88 to 2.73$)$ \\
\hline STD & $0.50(0.25$ to 0.97$) \S$ & $0.67(0.32$ to 1.38$)$ & 0.85 (0.37 to 1.91$)$ \\
\hline \multicolumn{4}{|l|}{ Males } \\
\hline Condom use at last sex & $0.70(0.47$ to 1.06$)$ & $0.41(0.26$ to 0.62$) \neq$ & $1.11(0.79$ to 1.93$)$ \\
\hline Frequent condom use & $0.62(0.39$ to 0.96$) \S$ & $0.14(0.08$ to 0.25$) \neq$ & $0.53(0.27$ to 1.06$)$ \\
\hline STD & $1.16(0.41$ to 3.31$)$ & 1.88 (0.66 to 5.42 ) & $2.07(0.62$ to 6.93$)$ \\
\hline \multicolumn{4}{|l|}{ Total } \\
\hline Condom use at last sex & $0.95(0.73$ to 1.25$)$ & $0.45(0.34$ to 0.60$) \neq$ & $1.18(0.82$ to 1.70$)$ \\
\hline Frequent condom use & $1.00(0.75$ to 1.34$)$ & $0.22(0.15$ to 0.31$) \neq$ & $1.04(0.67$ to 1.63$)$ \\
\hline STD & $0.64(0.36$ to 1.14$)$ & $0.95(0.52$ to 1.75$)$ & $1.08(0.54$ to 2.15$)$ \\
\hline
\end{tabular}

$\neq p \leq 0.0001,+p \leq 0.001,{ }^{*} p \leq 0.01, \S p \leq 0.05$

Comparison $\mathrm{A}=\mathrm{HC}$ (dual method $+\mathrm{HC}$ only) vs non- $\mathrm{HC}$ (condom only + non-contraceptive use) $(n=1443)$; Comparison $B=H C$ (dual method $+H C$ only) vs condom only $(n=1139)$; and Comparison $\mathrm{C}=$ dual method vs condom only $(\mathrm{n}=1006)$. aORs were adjusted by sex age, race, relationship tenure, and number of partners per year of sexual activity (log scale) only significant covariates were retained in the final multivariate model. 
Discussion Conclusions on whether condom use wanes among dual users may depend on the composition of groups compared. Future investigation of condom use among $\mathrm{HC}$ users should address this potential source of bias. If interpreted alongside each sub-groups' risk patterns for STD and unplanned pregnancy, the correlates of dual use can inform dual use interventions.

\section{P2-S1.09 ASSOCIATIONS BETWEEN EARLY SEXUAL DEBUT AND TWO TYPES OF SEXUAL RISK BEHAVIOUR IN NOVA SCOTIA ADOLESCENTS}

doi:10.1136/sextrans-2011-050108.287

D Langille, P Andreou, K Wilson. Dalhousie University, Halifax, Canada

Background This study sought to test associations between early sexual debut (first vaginal intercourse before age 15) and later sexual risk-taking among adolescents aged 15 to 19

Methods Self-report surveys were administered to 433 high school students in Yarmouth, Nova Scotia, Canada in May 2009. The surveys asked about general demographics, socioeconomic status, substance use, depression, peers' attitudes towards sex, and the sexual behaviours of students. Categorical principal components analysis was used to determine whether several of the outcome variables could be combined, and logistic regressions were used to assess the associations between predictor and outcome variables.

Results Two factors emerged among the risk behaviours: i) recreational sex (having many sexual partners, having sex while using substances and having casual partners); and; ii) inconsistent condom use, each of which was predicted by a distinct set of variables. Adjusted logistic regressions revealed that early sexual debut was associated with an increased risk of having used condoms inconsistently in the last year (OR 4.7; 95\% CI 1.0 to 21.5) and having had recreational sex in the same period (OR 2.5; 95\% CI 0.1 .0 to 6.4) among girls. The association between early debut and sexual risk behaviours was not seen in boys.

Conclusions Early sexual debut predicted of sexual risk taking among girls but not boys. Our findings offer a partial replication and expansion on recent research examining this issue. Asking high school students about age of their sexual debut and other factors might allow healthcare professionals to identify high risk individuals.

\section{P2-S1.10 IDENTIFYING KEY ELEMENTS DESCRIBING SEXUAL BEHAVIOUR IN THE DANISH POPULATION: A QUALITATIVE STUDY}

doi:10.1136/sextrans-2011-050108.288

${ }^{1} \mathrm{M} J$ Jørgensen, ${ }^{2} \mathrm{H}$ T Maindal, ${ }^{2} \mathrm{~F}$ Olesen, ${ }^{1} \mathrm{~B}$ Andersen. ${ }^{1}$ Randers Regional Hospital, Randers NØ, Denmark; ${ }^{2}$ Aarhus University, Aarhus C, Denmark

Background Surveying the sexual behaviour of the general population serves to identify key points of intervention, monitor the effect of such an intervention and interpret changes in the spread of sexually transmitted infections over time. Validated questionnaires describing sexual behaviour could be adapted from other countries, but due to cultural differences this could result in the need to add additional or other questions in order to describe the important Danish issues sufficiently. With a view to designing and initiating a sexual behaviour surveillance program in Denmark, the aim of this qualitative study was to identify points of particular importance to adolescents' sexual behaviour.
Method We conducted four semi-structured focus group interviews with a total of 19 sexually experienced adolescents aged 18 to 23 . Boys and girls were interviewed separately. Each group contained pupils from the same Danish Folk High School, but with different social and educational backgrounds. The interview guide was developed on the basis of literature reviews and hypotheses based on many years of experience with sexually transmitted infections from an epidemiological perspective as well as treatment of patients with sexually transmitted infections. Data were transcribed verbatim and analysed using qualitative description.

Results We identified four major categories of risk behaviour: 1) Alcohol consumption is associated with "no condom use". 2) Nights on the town and meetings in foreign counties or at festivals are associated with one night stands and often lead to unsafe sex. 3) Low self-esteem increases the risk of pushing one's personal boundaries, thus resulting in promiscuous sexual behaviour. 4) Increased sexual experience is associated with lack of condom use. Surprisingly, the informants did not consider drug abuse and internet dating to be triggers of unsafe sex see Abstract P2-S1.10 Figure 1.

Conclusion Danish adolescents identified four key elements that could lead to unsafe sex. These results differed slightly from our expectations and will be included in a sexual behaviour questionnaire to describe important elements influencing the sexual behaviour of Adolescents.

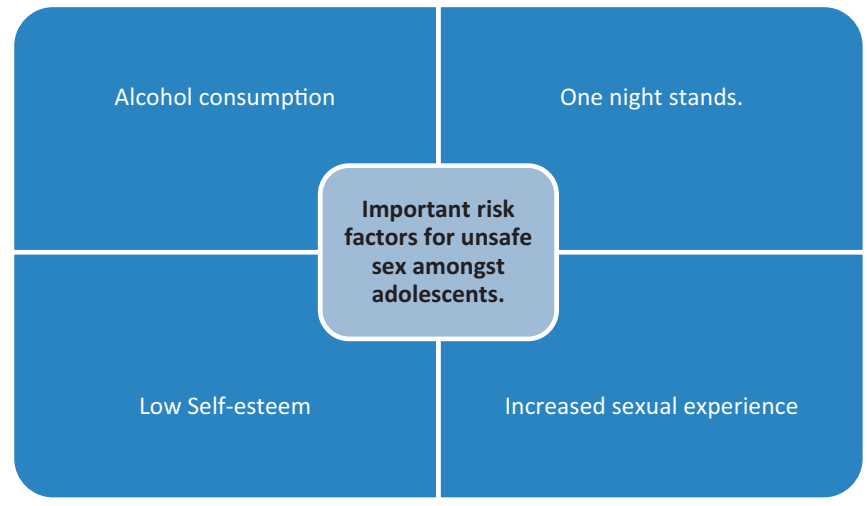

Abstract P2-S1.10 Figure 1 Important risk factors for unsafe sex among adolescents.

\section{P2-S1.11 FACTORS SURROUNDING LACK OF CONDOM USE AT FIRST INTERCOURSE AND LATER ONSET OF CONDOM USE: A STUDY OF COLLEGE-AGE MEN}

doi:10.1136/sextrans-2011-050108.289

${ }^{1} \mathrm{~L}$ Warner, ${ }^{1} \mathrm{~K} \mathrm{M},{ }^{1} \mathrm{~L}$ Gavin, ${ }^{2} \mathrm{M}$ Macaluso. ${ }^{1} \mathrm{CDC}$, Atlanta, USA; ${ }^{2}$ Cincinatti childrens center, Cincinatti, USA

Background Condom use at first coitus is associated with greater lifetime condom use. Little is known, however, about factors which influence non-use of condoms at first coitus.

Methods Data were analysed from a cross-sectional study on condom use behaviours conducted among 98 heterosexual male students attending two Georgia universities. Men were asked to recall condom use during first and subsequent coitus. Multivariable logistic regression was conducted to evaluate factors associated with non-use of condoms at first coitus and how non-use influenced their future condom beliefs and use.

Results Participant averaged 22.4 years at interview, 16.8 years at first intercourse (range: $13-23$ ), and 5.6 years (range:0-12) between first condom use and time of interview. Overall, 47 men (48\%) reported not using condoms at first coitus, and not initiating use until an average of 13 acts after sexual debut (med=5; range:1-100). 